\title{
Composição gravimétrica dos RCD para a etapa de acabamento em obras residenciais horizontais
}

\author{
$C \& D$ waste gravimetric composition for the final finishing \\ in horizontal residential buildings construction
}

\section{Marcelo Oliveira Caetano João Batista Oliveira Selbach Luciana Paulo Gomes}

\section{Resumo \\ $\mathbf{U}$}

ma parcela considerável dos resíduos de construção e demolição (RCD) gerados em um canteiro de obras é proveniente da etapa de acabamentos. Destes, uma grande quantidade são potencialmente recicláveis, com a possibilidade de aproveitamento no próprio local onde é gerado. Contudo, ações de reaproveitamento em obras não são rotineiras devido a fatores como dificuldades de identificação, segregação e classificação destes resíduos. Conhecer a composição gravimétrica qualitativa e quantitativa do RCD gerado por etapa da obra torna-se essencial para justificar tecnicamente e economicamente esse reaproveitamento. Assim, de forma a contribuir para o tema, a pesquisa proposta por este artigo objetivou a avaliar a composição gravimétrica dos RCD gerados na etapa de acabamentos de obras residenciais horizontais de padrão construtivo do programa habitacional Minha Casa Minha Vida. Desenvolveu-se uma pesquisa quantitativa com estudo de caso e coleta de dados primários em campo. Os resultados confirmaram que $92 \%$ dos RCD gerados na fase de acabamentos são passíveis de reciclagem. Nestes estão contidos: 39,13\% de madeira; 23,19\% de plásticos, papel e metal; 16,09\% de gesso; $12,99 \%$ de demolição (concreto, argamassa, cerâmica, etc); 8,38\% de embalagens contaminadas e $0,22 \%$ de fios. Como indicador de produção de RCD, a geração média para a fase de acabamentos representou $0,58 \mathrm{~m}^{3} / \mathrm{casa}$ ou $0,012 \mathrm{~m}^{3} / \mathrm{m}^{2}$ de área útil construída. Para acabamentos finos, o índice obtido foi de $0,46 \mathrm{~m}^{3} / \mathrm{casa}$ ou $0,0098 \mathrm{~m}^{3} / \mathrm{m}^{2}$ e para acabamentos brutos foi de $1,11 \mathrm{~m} / \mathrm{c}$ asa ou $0,0237 \mathrm{~m}^{3} / \mathrm{m}^{2}$.

Palavras-chaves: Resíduos de construção e demolição. RCD. Fase de acabamento. Condomínios resídenciais horizontais.

Marcelo Oliveira Caetano Universidade do Vale do Rio dos Sinos São Leopoldo - RS - Brasil

João Batista Oliveira Selbach Universidade do Vale do Rio dos Sinos São Leopoldo - RS - Brasil

Luciana Paulo Gomes Universidade do Vale do Rio dos Sinos São Leopoldo - RS - Brasil

Recebido em 07/08/15 Aceito em 16/12/15

\begin{abstract}
Construction and demolition $(C \& D)$ waste generated in the finishing stage of a construction project represents a large portion of the total waste generated on a construction site. Most of that waste can be recycled and reused on site. However, recycling actions on construction sites are not routinely used due to the difficulty to identify, separate and sort waste. Knowing the exact $C \& D$ waste quantity and quality per stage is essential for its technical and economic reuse. This case study presents a $C \& D$ waste gravimetric composition from the final finishing stage of a horizontal residential condominium construction. The results confirmed that $92 \%$ of the $C \& D$ waste from the final finishing stage could be recycled. The gravimetric composition showed that $39.13 \%$ of it was wood; $23.19 \%$ was plastic, paper and metal; $16.09 \%$ was gypsum and plaster; $12.99 \%$ was demolition waste (concrete, mortar, ceramic, etc.); $8.38 \%$ was contaminated waste and $0.22 \%$ was wire. The quantity results demonstrated a waste generation of $0.58 \mathrm{~m}^{3} / \mathrm{house}$ or $0.012 \mathrm{~m}^{3} / \mathrm{m}^{2}$ built area. The index obtained to the final fine finishing was $0.46 \mathrm{~m}^{3} / \mathrm{house}$ or $0.0098 \mathrm{~m}^{3} / \mathrm{m}^{2}$ and at the stage of coating with mortar and plaster was 1.11 $\mathrm{m}^{3} /$ house or $0.0237 \mathrm{~m}^{3} / \mathrm{m}^{2}$.
\end{abstract}

Keywords: Construction and demolition waste. C\&D waste. Final finishing. Horizontal residential condominium.

CAETANO, M. O.; SELBACH, J. B. O.; GOMES, L. P. Composição gravimétrica dos RCD para a etapa de acabamento em 51 obras residenciais horizontais. Ambiente Construído, Porto Alegre, v. 16, n. 2, p. 51-67, abr./jun. 2016. ISSN 1678-8621 Associação Nacional de Tecnologia do Ambiente Construído. http://dx.doi.org/10.1590/s1678-86212016000200079 


\section{Introdução}

O Programa Habitacional Minha Casa Minha Vida (MCMV) nasceu no Brasil em 2009 com o objetivo de construir moradias destinadas em grande parte à população de baixa renda, como uma solução para o déficit habitacional existente no país. Em consequência, ainda havia a expectativa da promoção da geração de emprego e renda aplicada ao setor de construção civil. Com um alto investimento de recursos financeiros do Governo Federal, essas metas foram atingidas nos anos subsequentes ao lançamento do Programa.

Contudo, de forma a padronizar a indústria de construção civil que atenderia a essa nova demanda do mercado nacional e garantiria certo nível de qualidade das edificações, foram criadas especificações mínimas exigidas para a construção dessas unidades habitacionais, que estão apresentadas no Quadro 1.

A coleção Habitare (Programa de Tecnologia De Habitação) apresenta uma série de volumes com artigos que divulgam pesquisas nacionais sobre esse tema. Inclui, por exemplo, papel do estado na habitação, avaliação pós-ocupação da habitação de interesse social, construção e meio ambiente e habitação em encostas.

$\mathrm{Na}$ área de resíduos de construção e demolição (RCD), o volume apresentado por Freitas et al. (2001), Habitação e meio ambiente, abordagem integrada em empreendimentos de interesse social, além de relatar conceitos, classificações, gerações e estratégias de reutilização, apresenta estudos que relacionam etapa de obra e prováveis gerações de resíduos.

\section{Quadro 1 - Especificações mínimas exigidas para unidades habitacionais construídas por meio do programa Minha Casa Minha Vida}

\begin{tabular}{|c|c|}
\hline Características gerais & Especificações mínimas do MCMV \\
\hline Revestimento interno & $\begin{array}{l}\text { Massa única, gesso (exceto banheiros, cozinhas ou áreas de serviço) ou concreto } \\
\text { regularizado para pintura. }\end{array}$ \\
\hline Revestimento externo & Massa única ou concreto regularizado para pintura. \\
\hline $\begin{array}{l}\text { Revestimento de áreas } \\
\text { molhadas }\end{array}$ & $\begin{array}{l}\text { Azulejo com altura mínima de } 1,50 \mathrm{~m} \text { em todas as paredes do banheiro, cozinha } \\
\text { e área de serviço. }\end{array}$ \\
\hline $\begin{array}{l}\text { Revestimento de áreas } \\
\text { comuns }\end{array}$ & Massa única, gesso ou concreto regularizado para pintura. \\
\hline Portas e ferragens & $\begin{array}{l}\text { Portas internas em madeira. Admite-se porta metálica no acesso à unidade. } \\
\text { Batente em aço ou madeira. }\end{array}$ \\
\hline Janelas & $\begin{array}{l}\text { Completa, de alumínio para regiões litorâneas ou meios agressivos e de aço para } \\
\text { demais regiões. }\end{array}$ \\
\hline Pisos & $\begin{array}{l}\text { Cerâmica nas áreas molhadas, com rodapé, e desnível máximo de } 15 \mathrm{~mm} . \\
\text { Cerâmica no hall e nas áreas de circulação internas. Cimentado alisado nos } \\
\text { demais cômodos e escadas. }\end{array}$ \\
\hline Pinturas & $\begin{array}{l}\text { Paredes internas e tetos em tinta PVA. Paredes de áreas molhadas ou externas } \\
\text { em tinta acrílica ou com textura impermeável. }\end{array}$ \\
\hline Pinturas das esquadrias & $\begin{array}{l}\text { Esquadrias de aço, esmalte sobre fundo preparador. Esquadrias de madeira em } \\
\text { esmalte ou verniz. }\end{array}$ \\
\hline Louças sanitárias & $\begin{array}{l}\text { Lavatório em louça sem coluna. Bacia sanitária em louça com caixa de descarga } \\
\text { acoplada. }\end{array}$ \\
\hline Tanque & $\begin{array}{l}\text { Capacidade mínima de } 20 \text { L, de concreto pré-moldado, PVC, granilite ou } \\
\text { mármore sintético. }\end{array}$ \\
\hline Pia de cozinha & Bancada de $1,20 \mathrm{~m}$ por $0,50 \mathrm{~m}$ com cuba de granilite ou mármore sintético. \\
\hline Torneiras & Em metal, cromadas, com acionamento por cruzeta ou alavanca. \\
\hline Circuitos elétricos & Circuitos independentes para chuveiro, tomadas e iluminação. \\
\hline Cobertura & $\begin{array}{l}\text { Sobre laje, em telha cerâmica ou de fibrocimento (espessura mínima de } 5 \mathrm{~mm} \text { ), } \\
\text { com estrutura de madeira ou metálica. Admite-se laje inclinada desde que } \\
\text { coberta com telhas. }\end{array}$ \\
\hline Sistema construtivo & $\begin{array}{l}\text { Aceitáveis as tecnologias inovadoras testadas e aprovadas conforme a NBR } \\
15575 \text { (ABNT, 2013) e homologadas pelo SINAT ou que comprovarem } \\
\text { desempenho satisfatório para a Caixa. }\end{array}$ \\
\hline
\end{tabular}

Fonte: Caixa Econômica Federal (2013). 
Como a metodologia e o sistema construtivo influenciam diretamente na geração de RCD, a correlação entre as pesquisas apresentadas por Freitas et al. (2001) e a padronização apresentada no Quadro 1 pode ser utilizada na estimativa da composição qualitativa dos RCD para habitações de interesse social.

Nesse aspecto deve-se considerar também que a etapa de acabamentos da obra (que inclui revestimentos com argamassa de reboco e gesso, pinturas e instalações de equipamentos e esquadrias) contribui significativamente para a quantidade de resíduos gerados pela obra. Nessa fase, o estudo de Lima e Lima (2009) demonstra que grande parcela dos resíduos de construção e demolição gerados pode ser classificada como classe A ou B conforme nomenclatura da Resolução $\mathrm{n}^{\circ} 307$ do Conama (CONSELHO..., 2002). O Quadro 2 apresenta uma adaptação dos dados obtidos pelos autores.

A Resolução no 307 do Conama (CONSELHO..., 2002) atribui responsabilidades para o poder público municipal e também para os geradores de resíduos. Além disso, define critérios para classificação e estabelecimento de possíveis destinações finais dos resíduos da construção e demolição no Brasil. Segundo a legislação, os RCD são classificados como:

(a) classe A (reutilizáveis ou recicláveis como agregados);

(b) classe B (recicláveis para outras destinações); (c) classe $\mathrm{C}$ (resíduos para os quais não foram desenvolvidas tecnologias ou aplicações economicamente viáveis); e

\section{(d) classe $\mathrm{D}$ (perigosos).}

Ainda entre as ferramentas legais e normas técnicas existentes no país aplicadas a resíduos de obra, destaca-se a Lei $n^{\circ} 12.305$, que instituiu a Política Nacional de Resíduos Sólidos (BRASIL, 2010) e a NBR 10004 (ABNT, 2004). Esta última aborda uma classificação dos resíduos sólidos em classe I (resíduos perigosos com características de inflamabilidade, corrosividade, reatividade, toxicidade e patogenicidade), classe II A (resíduos não perigosos não inertes) e classe II B (resíduos não perigosos inertes).

A geração, a composição gravimétrica e a classificação de resíduos de construção e demolição são amplamente abordadas na literatura. Sáez et al. (2014) relatam que a dificuldade de manuseio de RCD nos canteiros de obras não é uma novidade e continua sendo um problema ambiental. Contudo, entender a composição qualiquantitativa desses resíduos é essencial para otimização do seu gerenciamento.

A falta de dados de geração e composição de resíduos de construção e demolição é a grande barreira, conforme Llatas (2011), para o atendimento da meta da União Europeia para recuperação de $70 \%$ em peso dos RCD. Assim, a pesquisa propôs um modelo que permite a estimativa de geração durante a fase de concepção da obra.

\section{Quadro 2 - Estimativa qualitativa de geração de RCD para a fase de acabamentos}

\begin{tabular}{|c|c|c|}
\hline \multirow{2}{*}{ Etapa de acabamento } & $\begin{array}{c}\text { Tipo de resíduo } \\
\text { possivelmente gerado }\end{array}$ & $\begin{array}{c}\text { Classificação conforme a } \\
\text { Resolução n } \mathbf{3 0 7}\end{array}$ \\
\hline \multirow{2}{*}{ Revestimento interno/externo } & Argamassa & Classe A \\
\cline { 2 - 3 } & Gesso & Classe B \\
\hline \multirow{3}{*}{ Revestimentos cerâmicos } & Pisos e azulejos cerâmicos & Classe A \\
\cline { 2 - 3 } & $\begin{array}{c}\text { Pisos de madeira, papel, } \\
\text { papelão, plástico }\end{array}$ & Classe B \\
\cline { 2 - 3 } & Argamassa & Classe A \\
\hline \multirow{2}{*}{ Forros de gesso } & Placas de gesso acartonado & Classe B \\
\cline { 2 - 3 } & Classe D \\
\hline \multirow{2}{*}{ Pinturas } & Tintas, seladoras, vernizes, \\
& solventes & Classe D \\
\cline { 2 - 3 } & Latas metálicas com restos \\
de tinta & Classe D \\
\hline \multirow{2}{*}{ Coberturas } & Madeiras & Classe B \\
\cline { 2 - 3 } & $\begin{array}{c}\text { Cacos de telhas de } \\
\text { fibrocimento ou cerâmicas }\end{array}$ & Classe A \\
\cline { 2 - 3 } & Vernizes & Classe D \\
\hline
\end{tabular}

Fonte: adaptado de Lima e Lima (2009). 
Os resultados da aplicação do modelo proposto demonstraram que as maiores gerações de RCD estão relacionadas às etapas de pintura, limpeza do terreno e estrutura. Considerando as fases de acabamento, o modelo estimou geração de:
(a) $0,0127 \mathrm{~m}^{3} / \mathrm{m}^{2}$ (cobertura);
(b) $0,0007 \mathrm{~m}^{3} / \mathrm{m}^{2}$ (revestimentos);
(c) $0,0024 \mathrm{~m}^{3} / \mathrm{m}^{2}$ (carpintaria);
(d) $0,0029 \mathrm{~m}^{3} / \mathrm{m}^{2}$ (vidros); e
(e) $0,4193 \mathrm{~m}^{3} / \mathrm{m}^{2}$ (pinturas).

$\mathrm{O}$ autor ainda relatou diversos indicadores de geração de resíduos na Espanha utilizando a base de dados do Governo Espanhol de 2007. Segundo ele, em 2010 a Espanha gerou 39,27 milhões de toneladas de RCD. Em relação à composição gravimétrica, Llatas (2011) reporta que na Espanha $54 \%$ é cerâmica, $12 \%$ concreto, $7 \%$ rejeito, $5 \%$ rochas, $5 \%$ asfalto, $4 \%$ agregado, $4 \%$ madeira, $2,5 \%$ metais, $1,5 \%$ plástico, $0,5 \%$ vidro, $0,3 \%$ papel, $0,2 \%$ gesso e $4 \%$ outros. O autor também apresenta os indicadores de geração: $120,0 \mathrm{~kg} / \mathrm{m}^{2}$ para novas construções, $338,7 \mathrm{~kg} / \mathrm{m}^{2}$ para reabilitação $1129,0 \mathrm{~kg} / \mathrm{m}^{2}$ para demolição total e $903,2 \mathrm{~kg} / \mathrm{m}^{2}$ para demolição parcial.

Kern et al. (2015) citam que a quantificação desse tipo de resíduo pode ser um processo bastante difícil devido à grande variabilidade dos projetos, sistemas construtivos e materiais utilizados nas obras. De forma a contribuir para o tema, a pesquisa de Kern et al. (2015) abordou um modelo estatístico para determinar a quantidade de resíduos gerados na construção de edifícios e a influência do projeto e do sistema construtivo nesse contexto. Os autores demonstraram que a geração de RCD é influenciada não apenas por um incidente isolado, mas por uma combinação de fatores. Com características como a repetição de pavimentos, compacidade do prédio, práticas de reciclagem de resíduos no canteiro de obras, área de piso e sistema construtivo, foi possível estimar a quantidade de resíduos gerados de quase $70 \%$ das edificações estudadas.

Nesse mesmo tema a pesquisa de Ding e Xiao (2014) desenvolveu uma metodologia para a estimativa quantitativa e de composição dos RCD, porém em uma região com rápido desenvolvimento, como é o caso de Shanghai, na China. Para isso, os autores consideraram as variedades dos tipos de estruturas e sistemas construtivos utilizados na região em diferentes décadas.

Os mesmos pesquisadores apresentam também indicadores de geração de RCD no mundo. Alguns desses estudos estão a seguir resumidos: (a) Estados Unidos (2003): geração de 170 milhões de toneladas (39\% de origem residencial e $61 \%$ de origem não residencial);

(b) Grécia (2000): geração de 3,9 milhões de toneladas;

(c) Noruega (2002): geração de 1,3 milhão de toneladas. Destas, $67 \%$ eram de concreto;

(d) Espanha (2009): novas construções geraram $0,3076 \mathrm{~m}^{3} / \mathrm{m}^{2}$ e demolições $1,2676 \mathrm{~m}^{3} / \mathrm{m}^{2}$; e

(e) Coreia do Sul (1999): 8,63 milhões de toneladas.

Em Shanghai, Ding e Xiao (2014) descrevem que em 2012 foram gerados, aproximadamente, 13,71 milhões de toneladas de RCD. A composição gravimétrica dos resíduos de construção gerados no período era:
(a) $42,9 \%$ (concreto);
(b) $38,3 \%$ (tijolos e blocos);
(c) $11,2 \%$ (madeira);
(d) $6,5 \%$ (metal); e
(e) $1,1 \%$ (gesso)

Para os resíduos de demolição, a composição era:
(a) 63,8\% (tijolos e blocos);
(b) $22,6 \%$ (concreto);
(c) $8,4 \%$ (madeira);
(d) $3,1 \%$ (metal); e
(e) $2,1 \%$ (gesso)

Uma análise geral demonstra que $80 \%$ eram resíduos de concreto, tijolos e blocos. Ou seja, uma elevada parcela de resíduos que poderiam ser reciclados se fosse implantada medidas e tecnologias apropriadas de reciclagem.

$\mathrm{O}$ estudo ainda descreve uma geração per capita de RCD em Shanghai, para o ano de 2010, de 842 $\mathrm{kg} / \mathrm{hab}$. Esse dado se mostra maior em relação ao indicador de outros países como:
(a) Estados Unidos (cerca de $520 \mathrm{~kg} / \mathrm{hab} . \mathrm{ano}$ );
(b) Alemanha (cerca de $710 \mathrm{~kg} / \mathrm{hab} . \mathrm{ano}$ );
(c) Reino Unido (cerca de $500 \mathrm{~kg} / \mathrm{hab} . \mathrm{ano}$ );
(d) Austrália (cerca de $400 \mathrm{~kg} / \mathrm{hab} . a n o$ );
(e) Japão (cerca de 800 kg/hab.ano);
(f) Grécia (646 kg/hab.ano); e
(g) Portugal (186 kg/hab.ano) (DING; XIAO, 2014).

Ainda na China, outro estudo da composição gravimétrica dos resíduos gerados por casas e edifícios desmoronados devido ao terremoto 
Wenchuan, que ocorreu em 12 de maio de 2008 , na província de Sichuan, mostrou uma geração de:

(a) $54,59 \%$ de concreto;

(b) 39,76\% de tijolos;

(c) $2,20 \%$ de metal;

(d) 3,29\% de madeira; e

(e) $0,16 \%$ de outros resíduos (XIAO; XIE; ZHANG, 2012).

Mália, Brito e Bravo (2011) estimaram indicadores de geração de RCD considerando construções residenciais e não residenciais novas, demolição residencial e não residencial, reabilitação residencial e não residencial. A conclusão dos pesquisadores é que $80 \%$ do total de resíduos gerados (quando não são contabilizados os solos de escavação) é composto por concreto e materiais cerâmicos. Destacaram também a geração de resíduos de madeira e gesso relativos a etapas de acabamentos. Para edifícios com estrutura em madeira o indicador de geração de RCD ficou na faixa de 10 a $39 \mathrm{~kg} / \mathrm{m}^{2}$, e para edifícios com estrutura em concreto esse dado variou entre $44 \mathrm{e}$ $115 \mathrm{~kg} / \mathrm{m}^{2}$.

No trabalho de Sáez et al. (2014), os autores demonstraram que o uso de paredes com placas de gesso pode reduzir cerca de $15 \%$, em peso, da geração de RCD por metro quadrado de área construída, em comparação com o uso de alvenaria de tijolo tradicional. A taxa média de geração de resíduos considerando a construção com placas de gesso foi de $114,35 \mathrm{~kg} / \mathrm{m}^{2}$ ou $0,188 \mathrm{~m}^{3} / \mathrm{m}^{2}$, ao passo que para alvenaria de tijolo convencional esta taxa foi de $131,02 \mathrm{~kg} / \mathrm{m}^{2}$ ou $0,192 \mathrm{~m}^{3} / \mathrm{m}^{2}$.

Os autores ainda concluem que as atividades com alvenaria e de acabamentos são responsáveis por mais de $30 \%$ dos RCD gerados em todas as fases da obra, tanto em volume como em peso.

No Brasil, a Abrelpe (ASSOCIAÇÃO..., 2014) relata que foram coletadas, em 2014, 122.262 ton/dia de resíduos de construção e demolição, um índice de geração igual a $0,603 \mathrm{~kg} / \mathrm{hab}$.dia. Isso representa um aumento aproximado de $4,1 \%$ em relação a 2013 (117.435 ton/dia e geração per capita de 0,584 kg/hab.dia). O Estado do Rio Grande do Sul contribuiu com 13,5\% desse indicador com geração anual de 16.513 ton/dia ou $0,569 \mathrm{~kg} / \mathrm{hab}$.dia.

Em termos nacionais, são inúmeros os trabalhos que apresentam estudos sobre composição gravimétrica e indicadores de geração de RCD. Conforme Formoso et al. (2002), dois dos primeiros trabalhos nessa área foram desenvolvidos por Pinto, em 1989, e por Picchi, em 1993.
Formoso et al. (2002) investigaram, em 74 obras, a geração de RCD em diferentes regiões do Brasil. Os pesquisadores relatam a grande geração e heterogeneidade dos resíduos de construção e demolição no país. Ainda segundo os autores, grande parte desses resíduos pode ser evitada com ações gerenciais preventivas, como controle de processos e planejamento de produção.

Em um estudo sobre a geração de RCD na cidade de Recife, PE, Carneiro (2005) analisou dados em fases distintas de obras. Concluiu que a fase de produção de uma edificação responsável pelos maiores índices de geração de RCD é a fase de acabamento, precedida pelas fases estruturais e de fundações.

E, em Passo Fundo, RS, Bernardes et al. (2008) apresentam os resultados de classificação de RCD do município. Segundo os pesquisadores, do total coletado de RCD em Passo Fundo o maior percentual foi o da classe A, com 94,8, seguido pelo da classe $\mathrm{B}$, com $3,1 \%$, e pelo da classe $\mathrm{C}$, com $2,1 \%$. Os autores também concluem que esses quantitativos justificam uma política de reaproveitamento e reciclagem dos RCD do município, visto que mais de $94 \%$ podem ser reutilizados ou reciclados. Bernardes et al. (2008) ainda estimam um volume anual de RCD para o município igual a $27.130 \mathrm{~m}^{3}$, ou 36.897 ton. Isso equivale a uma geração per capita de 0,55 hg/hab.dia. Segundo o levantamento, desse total $42,5 \%$ são originados de reformas e demolições, $18,6 \%$ de obras em residências, $16,7 \%$ de limpeza de terreno, $11,1 \%$ de prédios em construção e $11,1 \%$ de terra bruta e escavações.

Já Miranda, Angulo e Careli (2009) descrevem um panorama de reciclagem de RCD no Brasil entre os anos de 1986 e 2008. No estudo, os autores realizaram um levantamento de canteiros de obras nos quais foi implantada a triagem dos resíduos de obra e concluíram acerca dos benefícios dessa ação. Além disso, ainda levantaram a taxa de crescimento, capacidade e condições operacionais das usinas de reciclagem de RCD no país. Entre os resultados, apresentou-se uma composição média das classes dos resíduos da construção civil para uma obra de edifício residencial multipiso, que compreendeu todo o período de execução (22 meses). Conforme os autores, nas duas obras estudadas (obra A, Levantamento de geração de RCD em toda a obra, e obra B, Resíduos apenas da fase de estruturas), a maior geração de RCD, em volume, foi classe A $(50,8 \%$ obra A e $37,5 \%$ obra B) e Madeira (31,4\% obra A e $42,0 \%$ obra B). A obra A ainda apresentou geração de $7,1 \%$ de resíduos de gesso, 6,9\% de papel; 3,2\% de plástico e $0,6 \%$ de metal. Em relação à composição de RCD por massa, os mesmos autores apresentam 
uma geração de resíduos de classe A que representa cerca de $80 \%$ do total de resíduos gerados na obra. A justificativa para esse dado é que os resíduos classe $\mathrm{B}$ (madeira, papel, plástico e metal) possuem densidade aparente inferior a 0,25 $\mathrm{t} / \mathrm{m}^{3}$, enquanto o resíduo classe A e o gesso possuem densidade aparente superior a $1,0 \mathrm{t} / \mathrm{m}^{3}$.

Em uma pesquisa realizada no Estado de São Paulo, referente aos anos de 1999 a 2002, apontouse que a etapa de acabamentos pode chegar a ser responsável por $59 \%$ do volume de resíduo gerado durante uma construção (NETO; SCHALCH, 2010).

Araújo e Carnaúba (2010) estudaram a composição gravimétrica e a massa específica dos RCD oriundos de obras verticais de Maceió. A pesquisa destaca que $96,44 \%$ do volume de RCD gerados são classificados como classe $\mathrm{A}$, podendo ser recicláveis como agregados. $\mathrm{O}$ estudo ainda apontou que $1,31 \%$ dos resíduos podem ser recicláveis para outras destinações (classe B); $1,79 \%$ não são recicláveis e $0,46 \%$ do volume de RCD foi considerado classe D (perigoso). A massa específica média determinada foi de 1,69 ton $/ \mathrm{m}^{3}$. Os autores ainda determinaram que dos resíduos classificados como classe A:

(a) $32,02 \%$ são concreto, alvenaria e argamassa;

(b) 20,80\%, concreto sem impurezas;

(c) 19,46\%, alvenaria sem revestimento cerâmico;

(d) 17,84\%, alvenaria sem impurezas;

(e) $9,06 \%$, alvenaria com presença de terra e vegetação; e

(f) $0,82 \%$, material asfáltico.

O diagnóstico de RCD em Fortaleza apresentado por Oliveira et al. (2011) demonstrou que os locais licenciados para recebimento desse tipo de resíduos sólido recebem cerca de 702 ton/dia. A estimativa é de 0,11 ton./hab.dia de RCD. O sistema movimenta $\mathrm{R} \$ 4,5$ milhões anualmente, e quase metade desse montante é aportado somente pela Prefeitura Municipal. Em relação à composição gravimétrica, os autores relataram as maiores proporções de geração de resíduos. Segundo Oliveira et al. (2011), 65\% do total de RCD gerados em Fortaleza podem ser classificados como classe A (38\% de argamassas, $14 \%$ de concreto e $13 \%$ de cerâmica vermelha). Conforme os pesquisadores, esses dados corroboram a afirmação de que as maiores perdas, em obras, ocorrem nas fases de concretagem, alvenaria emboço/reboco e revestimento.

Já a estimativa de geração de RCD proposta por Angulo et al. (2011) representou um total de 13.223 ton/ano. Destes, 2.329 ton/ano estão relacionados a construção e 10.894 ton/ano estão relacionados a demolição. Os pesquisadores investigaram a quantidade de RCD em um município de 36.300 habitantes na região noroeste do Estado de São Paulo. Foram avaliados dois métodos de quantificação, um indireto e outro direto, considerando a produção advinda dos agentes informais (reforma) e formais (construção). Angulo et al. (2011) concluíram que 91\% dos RCD foram classificados como classe A e $9 \%$ como classe B. Não foram identificados resíduos classe $\mathrm{C}$ e $\mathrm{D}$.

Araújo et al. (2011), com o objetivo de diagnosticar os resíduos gerados em canteiros de obra de diversas construtoras na cidade de João Pessoa/PB, atestam que os serviços de construção relacionados com a etapa de acabamento são responsáveis por uma grande geração de resíduos em obras.

Em Pelotas, RS, Tessaro, Sá e Scremin (2012) apresentam uma geração de RCD para o município igual a $315,08 \mathrm{~m}^{3}$ por ano, o que representa uma taxa de geração per capita de 1,23 kg/hab.dia e uma densidade igual de $1,28 \mathrm{ton} / \mathrm{m}^{3}$. Destes, $88 \%$ são resíduos classificados como classe A (fração mineral composta de argamassas, concretos, material cerâmico e solo natural), com potencial para serem reutilizáveis ou recicláveis na forma de agregado. Além disso, 11\% são resíduos classe B (madeira, metal, plástico, papel, vidro e gesso) e $1 \%$ é matéria orgânica.

E, ainda, Kern et al. (2015) apresentaram uma estimativa de geração de RCD em diferentes edificações localizadas na região metropolitana de Porto Alegre, RS. Os indicadores de geração de resíduos variaram de $0,05 \mathrm{~m}^{3} / \mathrm{m}^{2}$ até $0,37 \mathrm{~m}^{3} / \mathrm{m}^{2}$ de área total construída.

Todas as pesquisas nacionais e internacionais anteriormente abordadas demonstram uma grande quantidade de resíduos de construção e demolição com potencial para reutilização. Karpinsk (2009) cita que $83 \%$ dos RCD são potencialmente recicláveis no próprio setor da construção civil, com a possibilidade de aproveitamento no próprio local onde são gerados.

Na Europa, Ortiz, Pasqualino e Castells (2010) relatam que a Holanda está buscando incrementar seus processos de reciclagem de RCD. Dinamarca e Bélgica possuem índices de reciclagem desse tipo de resíduo superior a $80 \%$. Em Portugal e Espanha, o índice de reaproveitamento é de $40 \%$.

Evangelista, Costa e Zanta (2010) apresentam um estudo de viabilidade da reciclagem de resíduos classificados como classe A em obras brasileiras. Os autores confirmam o índice de $80 \%$ do total de 
RCD gerados em uma obra que são passíveis de reciclagem. Com esse quantitativo, estimam um retorno econômico para uma central de reciclagem de RCD no canteiro. O ganho estimado para os meses subsequentes à recuperação do investimento foi calculado em R $\$ 7.011,27 /$ mês. Ou seja, além de viabilidade ambiental, a reciclagem de resíduos classe A também é viável economicamente.

O trabalho de Miranda, Angulo e Careli (2009) demostrou que, no Brasil, após a resolução Conama 307 (CONSELHO..., 2002), a quantidade de usinas de reciclagem de RCD instaladas aumentou, mas essas usinas utilizam ainda um sistema simples de reciclagem. Em 2009 existiam pelo menos 47 usinas de reciclagem no país (24 públicas, $51 \%$ do total, e 23 privadas, $49 \%$ restante). Das 36 usinas que estão em operação ou em instalação, 15 (42\%) eram públicas e 21 (58\%) são privadas.

Mesmo assim, no país, ações de reciclagem de RCD nos canteiros de obra ainda são mínimas ou quase inexistentes, situação similar ao abordado por Ding e Xiao (2014) em sua pesquisa na China.

Em muitos casos, a dificuldade de reaproveitamento de RCD nos canteiros está diretamente relacionada à inexistência de um adequado inventário quantitativo e qualitativo desses resíduos. Sem isso, não existe possibilidade de segregação e classificação e, muito menos, de verificação da viabilidade econômica e técnica de reciclagem do resíduo na própria obra.

Outro fator limitante, como bem relatado nos diversos trabalhos encontrados na literatura, é a heterogeneidade dos resíduos devido à variabilidade dos insumos, sistemas construtivos e fases de obra. A estratificação da composição dos resíduos para cada etapa se torna imprescindível para se obter um adequado estudo do gerenciamento dos RCD.

Nesse contexto, a pesquisa proposta visa contribuir para a determinação quali-quantitativa dos RCD gerados na fase de acabamentos. Para tal, fez-se uma proposta de estudo de caso aplicado em obras residenciais de condomínios horizontais de padrão construtivo do programa habitacional Minha Casa Minha Vida.

\section{Método}

A pesquisa apresentada a seguir é enquadrada como uma pesquisa quantitativa e estudo de caso. Os dados coletados são dados primários, com levantamentos e medições executadas em campo, em escala real.

A metodologia é descrita em três etapas, que incluem descrição do estudo de caso e amostra da pesquisa, inventário qualitativo dos RCD gerados no empreendimento objeto de estudo de caso e inventário quantitativo.

\section{Estudo de caso e amostra da pesquisa}

O empreendimento estudado está localizado na cidade de Canoas no Estado do Rio Grande do Sul, Brasil. É composto por 430 casas de 2 pavimentos cada uma e área construída de cerca de $30.000 \mathrm{~m}^{2}$. Executado no sistema de alvenaria estrutural (com blocos de concreto) com laje moldada in loco, o foco do empreendimento era o segmento popular. As unidades são de 2 ou 3 dormitórios com 55 a 68 $\mathrm{m}^{2}$ de área privativa.

A obra encontrava-se com cerca de $65 \%$ de execução concluída, com a fase estrutural (alvenarias e lajes) e as vedações internas (divisões internas dos apartamentos) completamente executadas.

No momento dos levantamentos de campo para esta pesquisa, a fase da obra em andamento era a execução das instalações dos apartamentos (elétrica, hidráulica e gás), revestimentos internos (gesso liso sobre a alvenaria, massa única, revestimentos cerâmicos e pinturas) e externos (massa única), instalação de portas e janelas de alumínio. Paralelamente à execução das obras das edificações realizavam-se ainda as obras de infraestrutura do condomínio e edificações de uso comunitário (piscinas, quiosques, guarita).

Do total das 430 unidades realizou-se coleta de dados em 90 casas. Com isso, obteve-se uma amostra de $20 \%$ do total do condomínio. A Figura 1 apresenta o leiaute de implantação do empreendimento, com destaque para as unidades estudadas. 
Figura 1 - Leiaute simplificado da implantação do condomínio - Hachura das unidades habitacionais utilizados no estudo de caso

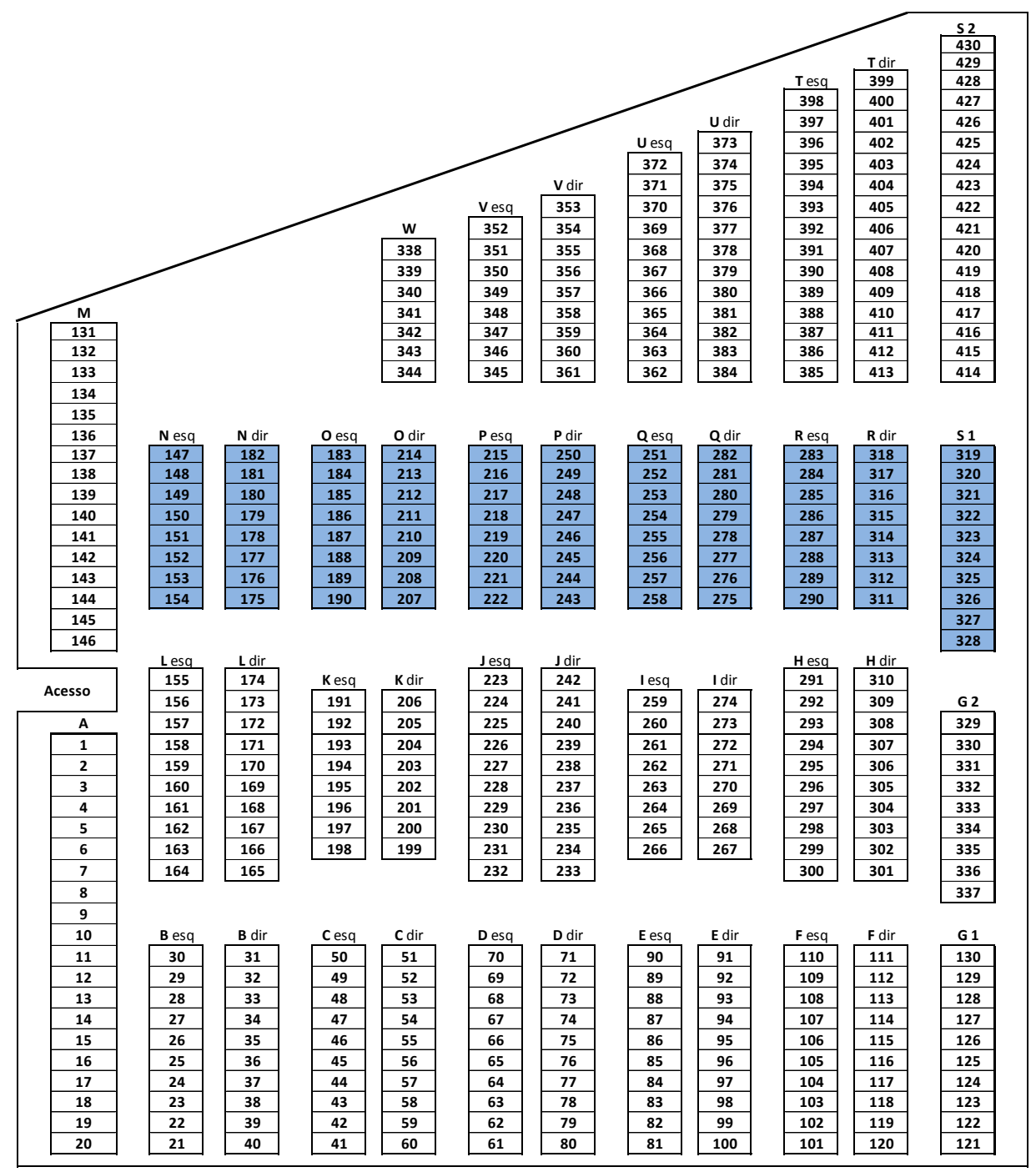

\section{Inventário qualitativo de RCD}

O inventário qualitativo do RCD gerado durante a execução dos serviços relacionados às etapas de acabamento do empreendimento tem o objetivo de identificar os materiais que compõem os resíduos e caracterizá-los conforme a classificação brasileira exposta na Resolução $\mathrm{n}^{\circ} 307$ (CONSELHO..., 2002) e na NBR 10004 (ABNT, 2004), por meio das classes de resíduos.

Os serviços em execução considerados como geradores de RCD provenientes das etapas de acabamento de obra foram os seguintes:

(a) revestimentos internos (pisos, tetos e paredes);

(b) revestimentos externos;

(c) instalação de esquadrias (madeira e metálicas); (d) instalações hidráulicas e elétricas executadas após os revestimentos;

(e) pinturas;

(f) instalação de louças e metais sanitários; e

(g) limpeza final.

Após o acompanhamento dos serviços foi elaborada a planilha de inventário qualitativo dos RCD gerados na obra e foram inventariados todos resíduos produzidos durante a execução das atividades relacionadas à fase de acabamento. Cabe ressaltar que durante o acompanhamento da execução dessas etapas foram considerados apenas os resíduos de produção, excluindo-se, por exemplo, restos de alimentos, papel higiênico e papel toalha.

Foram considerados resíduos os materiais desperdiçados devido a perdas durante e após a

58 Caetano, M. O.; Selbach, J. B. O.; Gomes, L. P. 
aplicação de demolições para ajustes necessários à execução dos serviços, materiais das embalagens dos insumos aplicados nos serviços e também materiais necessários ao transporte, proteção, preparo e acomodação desses insumos, até a sua efetiva instalação.

Para a estimativa dessa classificação, utilizaram-se as características físico-químicas apresentadas pelas fichas de informações de produtos químicos (FISPQ) dos produtos que compõem os resíduos. Não foram realizados ensaios de solubilização ou lixiviação dos resíduos encontrados durante o trabalho.

\section{Inventário quantitativo de RCD}

O inventário quantitativo dos RCD gerados durante a execução dos serviços relacionados às etapas de acabamento do empreendimento teve o objetivo de identificar os volumes gerados de cada tipo de resíduo nessa etapa construtiva. Justifica-se isso, pois o conhecimento do volume de RCD gerado é fundamental para o dimensionamento das etapas subsequentes no processo de gerenciamento dos RCD dentro do canteiro de obras.

Assim, a obtenção dos volumes foi realizada por meio do acompanhamento do processo de limpeza em conjunto com a equipe de trabalhadores responsável pela manutenção da limpeza das unidades, que acompanhou a segregação e remoção dos resíduos (RCD) até seu acondicionamento inicial e, assim, aferiu os volumes obtidos nas unidades do empreendimento. A falta de procedimentos e locais adequados existentes em obra para segregação dos RCD gerados impossibilitou a segregação completa dos resíduos pertencentes à classe $\mathrm{B}$, pelo que foi necessário o agrupamento dos volumes de resíduos compostos por plásticos, papéis e metais no levantamento dos dados.

Os volumes de RCD gerados nas unidades do empreendimento foram mensurados por meio de recipientes com volume de $0,018 \mathrm{~m}^{3}$ utilizados para sua coleta pela equipe de limpeza. Após a segregação inicial dos resíduos dentro da unidade onde se executa a limpeza, a equipe executava o recolhimento dos RCD para seu transporte e disposição em caçambas estacionárias dispostas pelo canteiro de obras, próximas às unidades onde se realiza a limpeza. Durante esse processo foram quantificados os recipientes necessários para se fazer o recolhimento dos RCD até a caçamba estacionária.

\section{Resultados \\ Inventário qualitativo de RCD}

O inventário qualitativo dos RCD gerados durante o estudo está representado no Quadro 3. Os itens que necessitam uma análise mais complexa quanto à classificação segundo a legislação nacional e/ou normas técnicas foram avaliados e justificados na sequência do texto.

Uma primeira discussão importante acerca do inventário qualitativo e análises das fichas de informações de segurança de produtos químicos (FISPQ) refere-se aos resíduos apresentados nesta pesquisa como classe II B (inerte) conforme referência da NBR 10004 (ABNT, 2004). Citamse, especificamente, resíduos de argamassa, rejunte e gesso.

Embora esse grupo de resíduos sólidos possa vir a ser enquadrado nas características "corrosividade e/ou reatividade", o que os caracterizariam como "resíduos sólidos classe I (perigoso)", a análise das FISPQ de alguns fabricantes demonstra baixa reatividade e solubilidade em água. Isso justifica inclusive a classificação da Conama $\mathrm{n}^{\mathbf{o}} 307$ (CONSELHO..., 2002) como resíduo com potencial de ser reciclado e/ou reutilizado (classe A ou B).

A vaselina sólida, após análise das FISPQ dos fabricantes, embora apresente o componente "mistura complexa de hidrocarbonetos de petróleo semissólida - CAS n ${ }^{\circ}$ 8009-03-8", foi considerada como classe II B - inerte. A análise da ficha do produto permite concluir que o material possui baixa toxicidade e insolubilidade em água. A classificação como classe $\mathrm{D}$, nesta pesquisa, é justificada porque esse resíduo não é passível de reciclagem. Porém, cabe uma ressalva quanto ao rigor nessa classificação. Em virtude da composição e análise da ficha do produto químico em questão, uma opção adequada poderia ser a classe $\mathrm{C}$, que segundo a legislação refere-se aos resíduos para os quais não foram desenvolvidas tecnologias ou aplicações economicamente viáveis que permitam a sua reciclagem ou recuperação.

Outro ponto a ser discutido refere-se à última alteração da Conama n 307 (CONSELHO..., 2002). A partir da Resolução Conama no 469 de 2015, as embalagens vazias de tintas imobiliárias devem ser classificadas como classe B, ou seja, recicláveis para outras destinações. No âmbito da legislação, consideram-se embalagens vazias de tintas imobiliárias aquelas cujo recipiente apresenta apenas filme seco de tinta em seu revestimento interno, sem acúmulo de resíduo de tinta líquida. 
Quadro 3 - Inventário qualitativo de resíduos conforme classificações Conama n 307 e NBR 10004 (Continua...)

\begin{tabular}{|c|c|c|c|c|}
\hline Serviço & Descrição & Resíduo gerado & $\begin{array}{c}\text { Classificação } \\
\text { Conama n⿳0 } \mathbf{3 0 7}\end{array}$ & Classificação NBR 10004 \\
\hline \multirow{14}{*}{$\begin{array}{l}\text { Revestimentos } \\
\text { internos } \\
\text { (pisos, tetos e } \\
\text { paredes) }\end{array}$} & \multirow{4}{*}{$\begin{array}{l}\text { Revestimento } \\
\text { interno em } \\
\text { massa única }\end{array}$} & Argamassa & Classe A & Classe II B - Inerte \\
\hline & & $\begin{array}{c}\text { Embalagem de papel } \\
\text { kraft }\end{array}$ & Classe B & Classe II A - Não inerte \\
\hline & & $\begin{array}{c}\text { Caliça (concreto + } \\
\text { cerâmica) }\end{array}$ & Classe A & Classe II B - Inerte \\
\hline & & Madeira (pallets) & Classe B & Classe II A - Não inerte \\
\hline & \multirow{7}{*}{$\begin{array}{l}\text { Revestimento } \\
\text { interno em } \\
\text { gesso liso }\end{array}$} & Gesso & Classe B & Classe II B - Inerte \\
\hline & & $\begin{array}{c}\text { Embalagem de papel } \\
\text { kraft }\end{array}$ & Classe B & Classe II A - Não inerte \\
\hline & & Caliça (concreto) & Classe A & Classe II B - Inerte \\
\hline & & $\begin{array}{c}\text { Adesivo copolímero } \\
\text { vinílico }\end{array}$ & Classe D & Classe I - Perigoso \\
\hline & & $\begin{array}{l}\text { Tambor de aço } \\
\text { contaminado }\end{array}$ & Classe D & Classe I - Perigoso \\
\hline & & Tela de poliéster & Classe B & Classe II B - Inerte \\
\hline & & Madeira (pallets) & Classe B & Classe II A - Não inerte \\
\hline & \multirow{3}{*}{$\begin{array}{c}\text { Revestimento } \\
\text { interno } \\
\text { cerâmico }\end{array}$} & Cerâmica & Classe A & Classe II B - inerte \\
\hline & & Embalagem de papelão & Classe B & Classe II A - Não inerte \\
\hline & & Argamassa & Classe A & Classe II B - Inerte \\
\hline \multirow{10}{*}{$\begin{array}{c}\text { Revestimentos } \\
\text { internos } \\
\text { (pisos, tetos e } \\
\text { paredes) }\end{array}$} & \multirow{4}{*}{$\begin{array}{c}\text { Revestimento } \\
\text { interno } \\
\text { cerâmico }\end{array}$} & $\begin{array}{c}\text { Embalagem de papel } \\
\text { kraft }\end{array}$ & Classe B & Classe II A - Não inerte \\
\hline & & Rejunte & Classe A & Classe II B - Inerte \\
\hline & & Embalagem plástica & Classe B & Classe II B - Inerte \\
\hline & & Madeira (pallets) & Classe B & Classe II A - Não inerte \\
\hline & \multirow{6}{*}{ Forro de gesso } & Placa de gesso & Classe B & Classe II B - Inerte \\
\hline & & Gesso & Classe B & Classe II B - Inerte \\
\hline & & $\begin{array}{c}\text { Embalagem de papel } \\
\text { kraft }\end{array}$ & Classe B & Classe II A - Não inerte \\
\hline & & Fibra de sisal & Classe B & Classe II B - Inerte \\
\hline & & Arame galvanizado & Classe B & Classe II B - Inerte \\
\hline & & Madeira (pallets) & Classe B & Classe II A - Não inerte \\
\hline \multirow{3}{*}{$\begin{array}{l}\text { Revestimentos } \\
\text { externos }\end{array}$} & \multirow{3}{*}{$\begin{array}{l}\text { Revestimento } \\
\text { externo em } \\
\text { massa única }\end{array}$} & Argamassa & Classe A & Classe II B - Inerte \\
\hline & & $\begin{array}{c}\text { Embalagem de papel } \\
\text { kraft }\end{array}$ & Classe B & Classe II A - Não inerte \\
\hline & & Madeira (pallets) & Classe B & Classe II A - Não inerte \\
\hline \multirow{9}{*}{$\begin{array}{l}\text { Instalação de } \\
\text { esquadrias } \\
\text { (madeira e } \\
\text { metálicas) }\end{array}$} & \multirow{6}{*}{$\begin{array}{l}\text { Colocação de } \\
\text { porta de } \\
\text { madeira }\end{array}$} & Serragem & Classe B & Classe II A - Não inerte \\
\hline & & Madeira & Classe B & Classe II A - Não inerte \\
\hline & & Espuma de poliuretano & Classe D & Classe I - Perigoso \\
\hline & & Lata de espuma de PU & Classe D & Classe I - Perigoso \\
\hline & & Embalagem de papelão & Classe B & Classe II A - Não inerte \\
\hline & & Embalagem plástica & Classe B & Classe II B - Inerte \\
\hline & \multirow{3}{*}{$\begin{array}{l}\text { Colocação de } \\
\text { esquadria de } \\
\text { alumínio }\end{array}$} & Argamassa & Classe A & Classe II B - Inerte \\
\hline & & Embalagem de papelão & Classe B & Classe II A - Não inerte \\
\hline & & Madeira & Classe B & Classe II A - Não inerte \\
\hline
\end{tabular}

60 Caetano, M. O.; Selbach, J. B. O.; Gomes, L. P. 
Quadro 3 - Inventário qualitativo de resíduos conforme classificações Conama n 307 e NBR 10004 (continuação)

\begin{tabular}{|c|c|c|c|c|}
\hline Serviço & Descrição & Resíduo gerado & $\begin{array}{c}\text { Classificação } \\
\text { CONAMA } \\
307 \\
\end{array}$ & $\begin{array}{c}\text { Classificação NBR } \\
10004\end{array}$ \\
\hline \multirow{9}{*}{$\begin{array}{l}\text { Instalações } \\
\text { hidráulicas }\end{array}$} & \multirow{9}{*}{$\begin{array}{c}\text { Colocação de } \\
\text { louças, flexíveis } \\
\text { e metais }\end{array}$} & Embalagem de papelão & Classe B & $\begin{array}{c}\text { Classe II A - Não } \\
\text { inerte }\end{array}$ \\
\hline & & Embalagem plástica & Classe B & Classe II B - Inerte \\
\hline & & Tubo de silicone & Classe D & Classe I - Perigoso \\
\hline & & Caliça (concreto + cerâmica) & Classe A & Classe II B - Inerte \\
\hline & & PVC & Classe B & Classe II B - Inerte \\
\hline & & Lâmina de serra de aço & Classe B & Classe II B - Inerte \\
\hline & & $\begin{array}{c}\text { Fita veda rosca } \\
\text { (Politetrafluoretileno) }\end{array}$ & Classe B & Classe II B - Inerte \\
\hline & & Tubo de adesivo PVC & Classe D & Classe I - Perigoso \\
\hline & & Papelão ondulado & Classe B & $\begin{array}{c}\text { Classe II A - Não } \\
\text { inerte }\end{array}$ \\
\hline \multirow{4}{*}{$\begin{array}{l}\text { Instalações } \\
\text { elétricas }\end{array}$} & \multirow{4}{*}{$\begin{array}{l}\text { Colocação de } \\
\text { acabamentos } \\
\text { elétricos }\end{array}$} & Fios & Classe B & Classe II B - Inerte \\
\hline & & Embalagem plástica & Classe B & Classe II B - Inerte \\
\hline & & Embalagem de papelão & Classe B & $\begin{array}{c}\text { Classe II A - Não } \\
\text { inerte }\end{array}$ \\
\hline & & Fita isolante PVC & Classe B & Classe II B - Inerte \\
\hline \multirow{11}{*}{ Pinturas } & \multirow{11}{*}{$\begin{array}{c}\text { Pintura Interna e } \\
\text { externa }\end{array}$} & Resíduo de tinta & Classe D & Classe I - Perigoso \\
\hline & & Massa corrida & Classe D & Classe I - Perigoso \\
\hline & & Aguarrás & Classe D & Classe I - Perigoso \\
\hline & & Lixa de papel & Classe B & $\begin{array}{l}\text { Classe II A - Não } \\
\text { inerte }\end{array}$ \\
\hline & & Vaselina sólida & Classe D & Classe II B - Inerte \\
\hline & & Embalagem plástica com tinta & Classe D & Classe I - Perigoso \\
\hline & & Lona plástica (PEBD) & Classe B & Classe II B - Inerte \\
\hline & & Lata de metal com tinta & Classe D & Classe I - Perigoso \\
\hline & & Pincéis e rolos contaminados & Classe D & Classe I - Perigoso \\
\hline & & Fita de papel adesiva - crepe & Classe B & Classe II B - Inerte \\
\hline & & Madeira (pallets) & Classe B & $\begin{array}{l}\text { Classe II A - Não } \\
\text { inerte }\end{array}$ \\
\hline \multirow{3}{*}{ Limpeza final } & \multirow{3}{*}{$\begin{array}{l}\text { Limpeza final } \\
\text { para entrega }\end{array}$} & $\begin{array}{c}\text { Embalagens plásticas de } \\
\text { produtos de limpeza }\end{array}$ & Classe B & Classe II B - Inerte \\
\hline & & $\begin{array}{l}\text { Utensílios de limpeza de } \\
\text { plástico }\end{array}$ & Classe B & Classe II B - Inerte \\
\hline & & Tecidos & Classe B & Classe II B - Inerte \\
\hline
\end{tabular}

Contudo, neste estudo de caso, as embalagens continham restos de tintas que caracterizaram certo grau de toxicidade e inflamabilidade. Por esse motivo, foram classificadas como classe D e classe I (perigoso). Percebe-se uma dificuldade em garantir um "filme seco de tinta" conforme nova redação da resolução. Essa nomenclatura, se mal interpretada, pode significar uma contaminação dos resíduos reciclados, o que inviabiliza seu reaproveitamento.

Já a classificação dos resíduos de poliuretano como classe D e classe I (perigoso) se deve à presença nas FISPQ de produtos químicos como di-isocianato de difenilmetano, isômeros e homólogos (CAS n ${ }^{\circ}$ 9016-87-9), cloroalcanos (CAS no 85535-85-9), dimetiléter (CAS n 115-106). O resíduo é considerado inflamável, e seus componentes podem representar efeitos graves à saúde, inclusive cancerígenos. É considerado nocivo por inalação e contato com pele e mucosas.

A classificação do silicone como perigoso também se deve à composição química do material. A FISPQ descreve, por exemplo, a presença de dimetilssiloxano hidroxiterminado (CAS n ${ }^{\circ} 63148$ 60-7), óleo de querosene tratado com hidrênio (CAS n ${ }^{\circ}$ 64742-47-8), metiltriacetoxissilano (CAS no 4253-34-3). Em relação à saúde, o produto pode provocar ou agravar dermatites. Altas 
concentrações podem provocar irritação aos olhos e problemas respiratórios.

Um fator relevante observado pela análise qualitativa do inventário refere-se à grande parte (cerca de 79\%) de resíduos pertencentes às classes A (resíduos reutilizáveis ou recicláveis como agregados) e B (resíduos recicláveis para outras destinações) conforme a classificação dada pela Resolução nº 307 (CONSELHO..., 2002). O que demonstra que grande parcela dos materiais gerados tem possibilidade de reutilização ou reciclagem, dentro ou fora do canteiro de obras. Isso reforça a importância do correto manejo dos RCD nas etapas de segregação, acondicionamento e transporte, para garantir seu reaproveitamento.

Em relação à estimativa quanto à classificação dos materiais conforme a NBR 10004 (ABNT, 2004) verifica-se que a maior parcela de materiais que compõem os RCD da unidade em estudo, ou seja, $48 \%$ pertencem à classe II B - Inerte. O restante são resíduos classificados como classe II A - não inerte $(33 \%)$ e classe I - perigoso (19\%). Esses dados confirmam o exposto por Karpinsk (2009) sobre a composição característica dos RCD gerados nas construções no Brasil, que, segundo o autor, possui baixa periculosidade dos componentes e grandes potenciais de reciclagem ou reutilização. Esse argumento também é mencionado em estudos no Brasil apresentados por Bernardes et al. (2008), Miranda, Angulo e Careli (2009), Araújo e Carnaúba (2010), Oliveira et al. (2011), Tessaro, Sá e Scremin (2012), Evangelista, Costa e Zanta (2010), e na China nos trabalhos de Ding e Xiao (2014) e Xiao, Xie e Zhang (2012).

\section{Inventário quantitativo de RCD}

O inventário quantitativo dos RCD gerados no empreendimento em estudo está representado no Quadro 4. É possível verificar o volume (em metros cúbicos) de resíduos coletados por tipo e agrupados de acordo com a classificação estabelecida pela Resolução $\mathrm{n}^{\circ} 307$ do Conama (CONSELHO..., 2002). O Quadro 4 também apresenta a quantidade de unidades habitacionais que contribui com o total de volume de RCD coletados.

A porcentagem de contribuição de resíduos para a amostra pesquisada está resumida na Tabela 1.

Quadro 4 - Volumes de RCD $\left(\mathrm{m}^{3}\right)$ coletados por conjunto de casas conforme classificação Conama $\mathrm{n}^{\circ}$ 307

\begin{tabular}{|c|c|c|c|c|c|c|c|c|}
\hline \multirow[b]{2}{*}{ Amostragem } & \multirow[b]{2}{*}{$\begin{array}{l}N^{0} \text { da } \\
\text { Casa }\end{array}$} & \multirow{2}{*}{$\begin{array}{c}\text { Classe A } \\
\begin{array}{c}\text { Demolição } \\
\left(\mathbf{m}^{3}\right)\end{array}\end{array}$} & \multicolumn{4}{|c|}{ Classe B } & \multirow{2}{*}{$\begin{array}{c}\text { Classe D } \\
\text { Perigosos } \\
\left(\mathrm{m}^{3}\right) \\
\end{array}$} & \multirow[b]{2}{*}{$\begin{array}{c}\text { Total } \\
\left(\mathbf{m}^{\mathbf{3}}\right)\end{array}$} \\
\hline & & & $\begin{array}{c}\text { Gesso } \\
\left(\mathbf{m}^{3}\right)\end{array}$ & $\begin{array}{c}\text { Madeira } \\
\left(\mathbf{m}^{3}\right)\end{array}$ & $\begin{array}{c}\text { Plástico / Papel / } \\
\text { Metal }\left(\mathbf{m}^{3}\right)\end{array}$ & $\begin{array}{l}\text { Fios } \\
\left(\mathbf{m}^{3}\right)\end{array}$ & & \\
\hline 1 & $\begin{array}{c}147 \mathrm{a} \\
154\end{array}$ & 0,16 & 0,10 & 1,60 & 1,04 & 0,02 & 0,65 & 3,57 \\
\hline 2 & $\begin{array}{c}175 \mathrm{a} \\
182\end{array}$ & 0,22 & 0,04 & 2,40 & 1,50 & 0,02 & 0,78 & 4,95 \\
\hline 3 & $\begin{array}{c}183 \mathrm{a} \\
190\end{array}$ & 0,25 & 0,04 & 1,60 & 1,24 & 0,02 & 0,59 & 3,73 \\
\hline 4 & $\begin{array}{c}207 a \\
214\end{array}$ & 0,22 & 0,11 & 2,00 & 0,98 & 0,01 & 0,39 & 3,70 \\
\hline 5 & $\begin{array}{c}215 \mathrm{a} \\
222\end{array}$ & 0,31 & 0,07 & 2,40 & 1,30 & 0,02 & 0,59 & 4,68 \\
\hline 6 & $\begin{array}{c}243 \mathrm{a} \\
250\end{array}$ & 0,11 & 0,13 & 0,80 & 0,91 & 0,03 & 0,52 & 2,49 \\
\hline 7 & $\begin{array}{c}251 \mathrm{a} \\
258\end{array}$ & 0,47 & 0,17 & 1,60 & 1,04 & 0,00 & 0,20 & 3,48 \\
\hline 8 & $\begin{array}{c}275 \mathrm{a} \\
282\end{array}$ & 0,59 & 0,22 & 2,00 & 0,85 & 0,00 & 0,26 & 3,91 \\
\hline 9 & $\begin{array}{c}183 \mathrm{a} \\
290\end{array}$ & 0,39 & 0,09 & 1,20 & 0,65 & 0,00 & 0,29 & 2,62 \\
\hline 10 & $\begin{array}{c}311 \mathrm{a} \\
318\end{array}$ & 1,80 & 3,20 & 2,40 & 1,24 & 0,00 & 0,07 & 8,70 \\
\hline 11 & $\begin{array}{c}319 \mathrm{a} \\
328\end{array}$ & 2,40 & 4,40 & 2,80 & 1,60 & 0,00 & 0,13 & 11,33 \\
\hline Total & - & 6,92 & $\mathbf{8 , 5 7}$ & 20,8 & 12,35 & $\mathbf{0 , 1 2}$ & $\mathbf{4 , 4 7}$ & 53,23 \\
\hline
\end{tabular}


Tabela 1 - Resumo dos volumes de RCD gerados conforme classificação Conama $n^{\circ} 307$

\begin{tabular}{|c|c|c|c|c|c|c|c|}
\hline \multirow{2}{*}{$\begin{array}{l}\text { Quantidade de casas } \\
\text { amostradas }\end{array}$} & \multicolumn{4}{|c|}{ Volume de $\mathrm{RCD}$ em $\mathrm{m}^{3}$ por classe } & \multicolumn{3}{|c|}{$\begin{array}{c}\text { Contribuição percentual de } \\
\text { RCD por classe }\end{array}$} \\
\hline & $A\left(\mathbf{m}^{3}\right)$ & $\mathbf{B}\left(\mathbf{m}^{3}\right)$ & $\mathbf{D}\left(\mathbf{m}^{3}\right)$ & $\begin{array}{l}\text { Total } \\
\left(\mathbf{m}^{3}\right)\end{array}$ & A $\%$ & В \% & D \% \\
\hline 8 & 0,16 & 2,76 & 0,65 & 3,57 & $4,5 \%$ & $77,3 \%$ & $18,2 \%$ \\
\hline 8 & 0,22 & 3,95 & 0,78 & 4,95 & $4,4 \%$ & $79,9 \%$ & $15,8 \%$ \\
\hline 8 & 0,25 & 2,89 & 0,59 & 3,73 & $6,8 \%$ & $77,5 \%$ & $15,7 \%$ \\
\hline 8 & 0,22 & 3,10 & 0,39 & 3,70 & $5,8 \%$ & $83,6 \%$ & $10,5 \%$ \\
\hline 8 & 0,31 & 3,79 & 0,59 & 4,68 & $6,5 \%$ & $81,0 \%$ & $12,5 \%$ \\
\hline 8 & 0,11 & 1,86 & 0,52 & 2,49 & $4,3 \%$ & $74,8 \%$ & $20,9 \%$ \\
\hline 8 & 0,47 & 2,81 & 0,20 & 3,48 & $13,5 \%$ & $80,9 \%$ & $5,6 \%$ \\
\hline 8 & 0,59 & 3,06 & 0,26 & 3,91 & $15,0 \%$ & $78,4 \%$ & $6,7 \%$ \\
\hline 8 & 0,39 & 1,94 & 0,29 & 2,62 & $14,9 \%$ & $74,0 \%$ & $11,2 \%$ \\
\hline 8 & 1,80 & 6,84 & 0,07 & 8,70 & $20,7 \%$ & $78,6 \%$ & $0,7 \%$ \\
\hline 10 & 2,40 & 8,80 & 0,13 & 11,33 & $21,2 \%$ & $77,7 \%$ & $1,1 \%$ \\
\hline TOTAL (90 casas) & 6,90 & 41,80 & 4,45 & 53,15 & $13 \%$ & $79 \%$ & $8 \%$ \\
\hline
\end{tabular}

Confirmando os resultados obtidos no inventário qualitativo, na análise da contribuição percentual (Figura 2) de cada classe no montante de RCD gerado durante $o$ estudo realizado no empreendimento, fica evidenciada a maciça representatividade de materiais pertencentes à classe B (como plásticos, papéis, metais e madeira).

A presença de materiais pertencentes à classe $\mathrm{A}$ (resíduos de demolição, solos e agregados) tornase de menor expressão nessa etapa de execução do empreendimento (12,99\%), devido à menor utilização de materiais que utilizam tais componentes. Nesse aspecto, observou-se em campo que a presença dos RCD de classe A é proveniente, na maior parte, de correções e reparos necessários à execução de serviços que não foram corretamente executados, ou devido à falta de correta sequência de atividades no andamento da construção, o que tornou necessária a demolição de alvenarias e lajes.

Assim a diferença quantitativa desses dados apresentados, em relação aos trabalhos encontrados na literatura (cerca de $90 \%$ de RCD classificados como classe A), deve-se ao fato de que o levantamento ocorreu especificamente para a etapa de acabamentos em condomínios residenciais horizontais. Por outro lado, nas pesquisas de Bernardes et al. (2008), Araújo e Carnaúba (2010), Angulo et al. (2011), Tessaro, Sá e Scremin (2012), Evangelista, Costa e Zanta (2010) e Ding e Xiao (2014) foi considerada a geração de RCD total da obra, sem divisão por etapas.

Devido à representatividade do volume de RCD pertencente à classe $\mathrm{B}$, fez-se uma estratificação dessas composições, conforme pode ser visualizada na Figura 3.

No volume de RCD da classe B coletados, observa-se a presença de maneira constante dos resíduos compostos por papéis, materiais plásticos e metálicos, com volume apresentando pouca variação dentre as diferentes coletas. Os volumes de gesso se destacam nas coletas finais devido ao fato de a etapa de revestimento em gesso liso estar em execução nessas unidades, mantido nas demais coletas um volume razoavelmente constante nas unidades de amostra.

Por outro lado, também deve ser observada a presença de grandes volumes de resíduos de madeira bruta. Esse grande volume deve-se a algumas características particulares desse empreendimento. A movimentação horizontal de insumos era executada por empilhadeiras com a utilização de pallets de madeira como base de apoio.

Contribuíram ainda para a geração de resíduos de madeira embalagens de fornecedores de argamassas, cerâmicas, louças e tintas, esquadrias danificadas e, em menor volume, bancadas e cavaletes construídos na obra para apoio à execução dos serviços internos como pintura e instalações suspensas.

Ainda em relação aos resíduos de madeira, Miranda, Angulo e Careli (2009) também relatam, em seu estudo em edifícios residenciais multipiso, uma faixa de geração entre $31,4 \%$ e $42,0 \%$. Esse índice contribuiu significativamente para a quantidade de resíduos classificados como classe $\mathrm{B}$, similar ao que foi observado em condomínios horizontais. 
Figura 2 - Inventário quantitativo dos RCD gerados na área de estudo

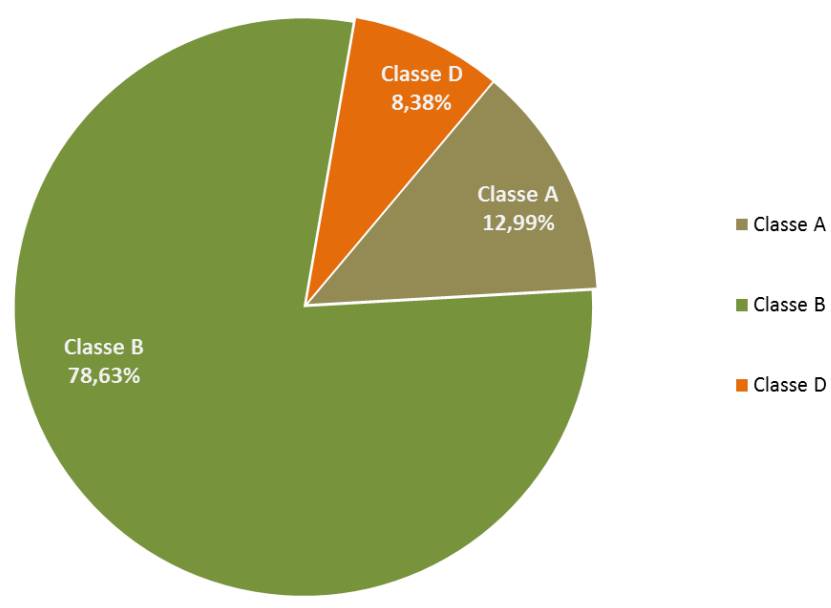

Figura 3 - Estratificação dos RCD gerados na área de estudo

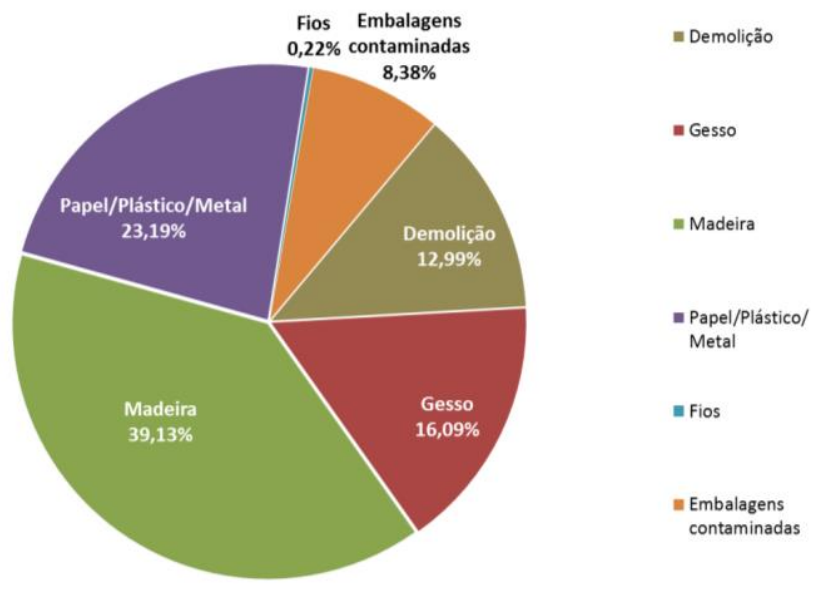

Dessa forma, embora a composição gravimétrica quantitativa demonstrada nas Figuras 2 e 3 seja bem diferente daquelas apresentadas nos trabalhos de Bernardes et al. (2008), Araújo e Carnaúba (2010), Angulo et al. (2011), Mália, Brito e Bravo (2011), Tessaro, Sá e Scremin (2012), Oliveira et al. (2011), Ding e Xiao (2014) e Xiao, Xie e Zhang (2012), percebe-se que $92 \%$ dos resíduos de acabamentos gerados poderiam ser reciclados se fossem implantadas medidas e tecnologias apropriadas de reciclagem. Esse resultado corrobora as pesquisas anteriormente citadas.

\section{Resíduos de acabamento para obras residenciais horizontais}

$\mathrm{Na}$ determinação do inventário quantitativo dos RCD gerados pela obra objeto de estudo de caso, percebeu-se uma diferença entre as quantidades de resíduos geradas na etapa de acabamento bruto (revestimentos com argamassa de reboco e gesso) e o acabamento fino (pinturas e instalações de equipamentos e esquadrias). Essa divisão já fora percebida e proposta por Martins (2009).

No caso desta pesquisa, a execução dos acabamentos finos, apesar de também acontecer em diferentes etapas nas unidades em estudo, apresentou uma geração mais uniforme de resíduos. Isso ocorreu principalmente por se tratar, em sua maioria, de instalação de equipamentos prontos, que geram RCD compostos em grande parte de materiais recicláveis, como plásticos e papéis, provenientes de embalagens.

A partir disso, para análise dos dados quantitativos da geração de resíduos de acabamento aplicável a obras residenciais horizontais, fez-se uma divisão dos dados por grupos. A Tabela 2 apresenta os resultados estratificados para a geração de RCD provenientes de acabamentos finos e a Tabela 3 demonstra os dados de geração de RCD originados de acabamentos brutos.

A comparação entre as fontes de geração de RCD demonstra um indicador de produção média de

64 Caetano, M. O.; Selbach, J. B. O.; Gomes, L. P. 
resíduos de acabamento fino igual a $0,46 \mathrm{~m}^{3} / \mathrm{casa}$ ou $0,0098 \mathrm{~m}^{3} / \mathrm{m}^{2}$ de área útil construída, considerando as unidades habitacionais com $47 \mathrm{~m}^{2}$ de área construída. Já para a geração de RCD originados dos serviços de acabamento bruto, a produção média foi de $1,11 \mathrm{~m}^{3} /$ casa ou 0,0237 $\mathrm{m}^{3} / \mathrm{m}^{2}$ de área útil construída.

Considerando a geração total para a fase de acabamentos, o indicador é de $0,58 \mathrm{~m}^{3} /$ casa ou $0,012 \mathrm{~m}^{3} / \mathrm{m}^{2}$. Esse dado é diferente da estimativa de geração de $0,4351 \mathrm{~m}^{3} / \mathrm{m}^{2}$ de RCD das fases de acabamento propostas pelo modelo de Llatas (2011). Essa diferença pode ser justificada pelo tipo construtivo. Os estudos de Llatas (2011) foram realizados em edificações verticais na Espanha, enquanto esta pesquisa abordou edificações horizontais. Além disso, conforme o próprio pesquisador, a comparação entre dados de geração de RCD em diferentes países se torna difícil porque esse dado depende da tecnologia construtiva e dos procedimentos de construção utilizados.

Para a estimativa em massa dos RCD, adotou-se a densidade aparente proposta por Miranda, Angulo e Careli (2009) para as classes A e B igual a 1,0 $\mathrm{t} / \mathrm{m}^{3}$ e $0,25 \mathrm{t} / \mathrm{m}^{3}$ respectivamente. $\mathrm{O}$ indicador de geração de RCD para o estudo de caso foi calculado em 199,56 kg/casa ou 4,25 kg/m².
Novamente, devido a esses dados estarem relacionados a apenas um tipo específico de obra e limitado à etapa de acabamentos, esse indicador está bem inferior aos índices apresentados por Máli, Brito e Bravo (2011), Ding e Xiao (2014) e Sáez et al. (2014). Nesta última pesquisa, os autores apresentaram faixas de geração de RCD relatadas entre 0,08 e $0,97 \mathrm{~m}^{3} / \mathrm{m}^{2}$ e entre 115,29 e $255,49 \mathrm{~kg} / \mathrm{m}^{2}$ (Espanha entre os anos de 2000 e 2013), 40,70 kg/m² (China para o ano de 2013), $0,20 \mathrm{~m}^{3} / \mathrm{m}^{2}$ (Israel para o ano de 2010). Mália, Brito e Bravo (2011) apresentaram dados de geração de resíduos em edifícios com estrutura em concreto variando entre 44 e $115 \mathrm{~kg} / \mathrm{m}^{2}$.

\section{Conclusões}

A pesquisa (estudo de caso em obras residenciais horizontais de padrão construtivo do programa habitacional Minha Casa Minha Vida) apresentada demonstrou que $92 \%$ dos resíduos de construção e demolição gerados na etapa de acabamentos são passíveis de reciclagem. Qualitativamente, os resíduos de madeiras representaram $39,13 \%$ do total de resíduos gerados, seguidos de $23,19 \%$ de reciclados (plástico, metal e papel), 16,09\% de resíduos de concreto, argamassa e cerâmica, 8,38\% de resíduos contaminados e $0,22 \%$ de fios.

Tabela 2 - Volume de RCD gerados na execução de acabamento fino

\begin{tabular}{|c|c|c|c|c|c|c|c|}
\hline Amostragem & $\begin{array}{l}\text { Quant. } \\
\text { Casas }\end{array}$ & $\begin{array}{c}\text { Classe A } \\
\mathbf{m}^{3} \\
\end{array}$ & $\begin{array}{c}\text { Classe B } \\
\mathbf{m}^{3}\end{array}$ & $\begin{array}{c}\text { Classe D } \\
\mathbf{m}^{3} \\
\end{array}$ & Total $\mathbf{m}^{3}$ & $\begin{array}{c}\text { RCD } \\
\mathbf{m}^{3} / \text { casa }\end{array}$ & $\begin{array}{l}\mathrm{RCD} \mathrm{m} \mathrm{m}^{3} / \mathrm{m}^{2} \\
\text { de área útil }\end{array}$ \\
\hline 1 & 8 & 0,16 & 2,76 & 0,65 & 3,57 & 0,45 & 0,0095 \\
\hline 2 & 8 & 0,22 & 3,95 & 0,78 & 4,95 & 0,62 & 0,0132 \\
\hline 3 & 8 & 0,25 & 2,89 & 0,59 & 3,73 & 0,47 & 0,0099 \\
\hline 4 & 8 & 0,22 & 3,10 & 0,39 & 3,70 & 0,46 & 0,0099 \\
\hline 5 & 8 & 0,31 & 3,79 & 0,59 & 4,68 & 0,59 & 0,0125 \\
\hline 6 & 8 & 0,11 & 1,86 & 0,52 & 2,49 & 0,31 & 0,0066 \\
\hline 7 & 8 & 0,47 & 2,81 & 0,20 & 3,48 & 0,43 & 0,0093 \\
\hline 8 & 8 & 0,59 & 3,06 & 0,26 & 3,91 & 0,49 & 0,0104 \\
\hline 9 & 8 & 0,39 & 1,94 & 0,29 & 2,62 & 0,33 & 0,0070 \\
\hline \multicolumn{2}{|c|}{ Media $\mathrm{m}^{3} \mathrm{RCD}$} & 0,30 & 2,91 & 0,47 & 3,68 & 0,46 & 0,0098 \\
\hline \multicolumn{2}{|c|}{ Desvio padrão } & 0,15 & 0,71 & 0,20 & 0,81 & 0,10 & 0,0022 \\
\hline \multicolumn{2}{|c|}{ Coefic. de variação } & $51 \%$ & $24 \%$ & $42 \%$ & $22 \%$ & $22 \%$ & $22 \%$ \\
\hline
\end{tabular}

Tabela 3 - Volume de RCD gerados na execução de acabamento bruto

\begin{tabular}{|c|c|c|c|c|c|c|c|}
\hline Amostragem & $\begin{array}{l}\text { Quant. } \\
\text { Casas }\end{array}$ & $\begin{array}{c}\text { Classe A } \\
\mathbf{m}^{3} \\
\end{array}$ & $\begin{array}{c}\text { Classe B } \\
\mathbf{m}^{3}\end{array}$ & $\begin{array}{c}\text { Classe D } \\
\mathbf{m}^{3} \\
\end{array}$ & Total $\mathbf{m}^{3}$ & $\begin{array}{c}\text { RCD } \\
\mathrm{m}^{3} / \text { casa }\end{array}$ & 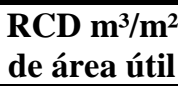 \\
\hline 10 & 8 & 1,80 & 6,84 & 0,07 & 8,70 & 1,09 & 0,0232 \\
\hline 11 & 10 & 2,40 & 8,80 & 0,13 & 11,33 & 1,13 & 0,0241 \\
\hline \multicolumn{2}{|c|}{ Média $\mathrm{m}^{3} \mathrm{RCD}$} & 2,10 & 7,82 & 0,10 & 10,02 & 1,11 & 0,0237 \\
\hline \multicolumn{2}{|c|}{ Desvio padrão } & 0,42 & 1,39 & 0,05 & 1,86 & 0,03 & 0,0007 \\
\hline \multicolumn{2}{|c|}{ Coefic. de variação } & $20 \%$ & $18 \%$ & $47 \%$ & $19 \%$ & $3 \%$ & $3 \%$ \\
\hline
\end{tabular}


A maior quantidade de madeira deve-se à peculiaridade da obra (horizontal) e a necessidade de utilização de pallets como base de apoio e de empilhadeiras para movimentações horizontais $\mathrm{e}$ armazenamentos de insumos e materiais. Já a quantidade de resíduos classe $\mathrm{B}$ está relacionada ao descarte das embalagens dos insumos como revestimentos, por exemplo.

A presença dos RCD de classe A é proveniente, na maior parte, de reparos em alvenarias e lajes. E, finalmente, a geração de resíduos contaminados (classe D) está associada a embalagens e insumos relacionados às etapas de pintura, hidráulica e instalação de esquadrias (tintas, colas, espuma, poliuretano, silicone, etc.).

O levantamento quantitativo dos RCD mostrou um índice de geração de RCD para a etapa de acabamentos igual a $0,58 \mathrm{~m}^{3} / \mathrm{casa}$ ou $0,012 \mathrm{~m}^{3} / \mathrm{m}^{2}$ de área útil construída, considerando as unidades habitacionais com $47 \mathrm{~m}^{2}$ de área construída. Em massa esses índices foram estimados em 199,56 $\mathrm{kg} / \mathrm{casa}$ ou $4,25 \mathrm{~kg} / \mathrm{m}^{2}$. Para acabamentos finos o índice obtido foi de $0,46 \mathrm{~m}^{3} /$ casa ou $0,0098 \mathrm{~m}^{3} / \mathrm{m}^{2}$, e para acabamentos brutos foi de $1,11 \mathrm{~m}^{3} /$ casa ou $0,0237 \mathrm{~m}^{3} / \mathrm{m}^{2}$.

\section{Referências}

ANGULO, S. C. et al. Resíduos de construção e demolição: avaliação de métodos de quantificação. Engenharia Sanitária e Ambiental, v. 16, n. 3, p. 299-306, jul./set. 2011.

ARAÚJO, N. M. C. et al. Metodologia para gestão de resíduos em canteiros de obra de edificações verticais. In: SEMANA DE CIÊNCIA E TECNOLOGIA DO IFPB CAMPUS JOÃO PESSOA, 7., João Pessoa, 2011. Anais... João Pessoa, 2011.

ARAÚJO, N. M. C.; CARNAÚBA, T. M. G. V. Composição gravimétrica e massa específica dos RCD oriundos de obras de edificações verticais de Maceió. In: ENCONTRO NACIONAL DE TECNOLOGIA DO AMBIENTE CONSTRUÍDO, 13., Canela, 2010. Anais... Canela: ANTAC, 2010.

ASSOCIAÇÃO BRASILEIRA DE NORMAS TÉCNICAS. NBR 10004: resíduos sólidos: classificação. Rio de Janeiro, 2004.

ASSOCIAÇÃO BRASILEIRA DE NORMAS TÉCNICAS. NBR 15575: edificações habitacionais: desempenho. Rio de Janeiro: ABNT, 2013.
ASSOCIAÇÃO BRASILEIRA DAS EMPRESAS DE LIMPEZA PÚBLICA E RESÍDUOS ESPECIAIS. Panorama dos resíduos sólidos no Brasil 2014. 120 p. 2014. Disponível em: <http://www.abrelpe.org.br/Panorama/panorama20 14.pdf>. Acesso em: 07 jan. 2016.

BERNARDES, A. et al. Quantificação e Classificação dos Resíduos da Construção e Demolição Coletados no Município de Passo Fundo, RS. Ambiente Construído, Porto Alegre, V. 8, n. 3, p. 65-76, jul./out. 2008.

BRASIL. Lei $\mathbf{n}^{\mathbf{0}} \mathbf{1 2 . 3 0 5}$, de 2 de agosto de 2010. Brasil. Disponível em:

<http://www.planalto.gov.br/ccivil_03/_ato20072010/2010/lei/112305.htm>. Acesso em: 14 jan. 2013.

\section{CAIXA ECONÔMICA FEDERAL. Manual} Minha Casa Minha Vida. Jun. 2013. Disponível em:

<http://www.adh.pi.gov.br/minha_casa_minha_vid a.pdf $>$. Acesso em: 07 jan. 2016.

CARNEIRO, F. P. Diagnóstico e ações da atual situação dos resíduos de construção e demolição na cidade do Recife. João Pessoa, 2005. $131 \mathrm{f}$. Dissertação (Mestrado em Engenharia Civil) Escola de Engenharia, Universidade Federal da Paraíba, 2005.

\section{CONSELHO NACIONAL DO MEIO}

AMBIENTE. Resolução $\mathbf{n}^{\circ}$ 307, de 5 de julho de 2002, que estabelece diretrizes, critérios e procedimentos para a gestão dos resíduos da construção civil. Brasília, 2002. Disponível em: <http://www.mma.gov.br/port/conama/legiabre.cf m?codlegi=307>. Acesso em: 7 jan. 2016.

DING, T.; XIAO, J. Estimation of building-related construction and demolition waste in Shanghai. Waste Management, v. 34, p. 2327-2334, 2014.

EVANGELISTA, P. P. A.; COSTA, D. B.; ZANTA, V. M. Alternativa sustentável para destinação de resíduos de construção classe A: sistemática para reciclagem em canteiros de obras. Ambiente Construído, Porto Alegre, v. 10, n. 3, p. 23-40, jul./set. 2010.

FORMOSO, C. T. et al. Material waste in building industry: main causes and prevention. Journal of Construction Engineering and Management, v. 128, n. 4, p. 316-325, 2002.

FREITAS, C. G. L. et al. Habitação e meio ambiente: abordagem integrada em empreendimentos de interesse social. São Paulo: IPT, 2001.

KARPINSK, L. A. Gestão diferenciada de resíduos da construção civil: uma abordagem ambiental. Porto Alegre: ediPUCRS, 2009. 
KERN, A. P. et al. Waste generated in high-rise buildings construction: a quantification model based on statistical multiple regression. Waste Management, v. 39, p. 35-44, 2015.

LIMA, R. S.; LIMA, R. R. R. Guia para elaboração de projeto de gerenciamento de resíduos da construção civil. Série de publicações temáticas do CREA-PR, 2009.

LLATAS, C. A Model for quantifying construction waste in projects according to the European waste list. Waste Management, v. 31, n. 6, p. 1261-1276, 2011.

MÁLIA, M.; BRITO, J. de; BRAVO, M. Indicadores de resíduos de construção e demolição para construções residenciais novas. Ambiente Construído, Porto Alegre, v. 11, n. 3, p. 117-130, jul./set. 2011.

MARTINS, A. R. B. Caracterização e avaliação de poeiras presentes em canteiros de obras de edificações verticais. 2009. Dissertação (Mestrado em Engenharia Civil) - Escola de Engenharia, Universidade de Pernambuco, João Pessoa, 2009.

MIRANDA, L. F. R.; ANGULO, S. C.; CARELI, É. D. A reciclagem de resíduos de construção e demolição no Brasil: 1986-2008. Ambiente Construído, Porto Alegre, v. 9, n. 1, p. 57-71, jan./mar. 2009.
NETO, J. da C.; SCHALCH, V. Gestão dos resíduos de construção e demolição: estudo da situação no município de São Carlos-SP, Brasil. Revista Engenharia Civil, v. 36, p. 41-50, 2010.

OLIVEIRA, M. E. D. de et al. Diagnóstico da geração e da composição dos RCD de Fortaleza/CE. Engenharia Sanitária e Ambiental, v. 16, n. 3, 219-224, jul./set. 2011.

ORTIZ, O.; PASQUALINO, J. C.; CASTELLS, F. Environmental performance of construction waste: comparing three scenarios from a case study in Catalonia, Spain. Waste Management, v. 30, n. 4, p. 646-54, 2010.

SÁEZ, P. V. et al. Assessing the accumulation of construction waste generation during residential building construction works. Resources,

Conservation and Recycling, v. 93, p. 67-74, 2014.

TESSARO, A. B.; SÁ, J. S.; SCREMIN, L. B. Quantificação e classificação dos resíduos procedentes da construção civil e demolição no município de Pelotas, RS. Ambiente Construído, Porto Alegre, v. 12, n. 2, p. 121-130, abr./jun. 2012.

XIAO, J.; XIE, H.; ZHANG, C. Investigation on building waste and reclaim in Wenchuan earthquake disaster area. Resources,

Conservation and Recycling, v. 61, n. 4, p. 109117, 2012.

\footnotetext{
Marcelo Oliveira Caetano

Programa de Pós-Graduação em Engenharia Civil, Unidade Acadêmica de Pesquisa e Pós-Graduação | Universidade do Vale do Rio dos Sinos | Av. Unisinos, 950, Cristo Rei | São Leopoldo - RS - Brasil | Caixa Postal 275 | CEP $93022-000$ | Tel.: (51) $3590-8464$ Ramal 5060 | E-mail: mocaetano@unisinos.br

João Batista Oliveira Selbach

Laboratório de Saneamento Ambiental | Universidade do Vale do Rio dos Sinos | São Leopoldo - RS - Brasil | E-mail: jselbach@gmail.com

Luciana Paulo Gomes

Programa de Pós-Graduação em Engenharia Civil, Unidade Acadêmica de Pesquisa e Pós-Graduação | Universidade do Vale do Rio dos Sinos | E-mail: lugomes@unisinos.br
}

Revista Ambiente Construído

Associação Nacional de Tecnologia do Ambiente Construído

Av. Osvaldo Aranha, $99-3^{\circ}$ andar, Centro

Porto Alegre - RS - Brasil

CEP $90035-190$

Telefone: +55 (51) 3308-4084

Fax: +55 (51) 3308-4054

www.seer.ufrgs.br/ambienteconstruido

E-mail: ambienteconstruido@ufrgs.br 